Mailson Lima NAZARÉ; Paula Mayara Rodrigues do NASCIMENTO; Rafael Santos PENHA

\title{
GRANDES PROJETOS EM BARCARENA-PA: IMPACTOS SOCIOAMBIENTAIS CAUSADOS PELAS ATIVIDADES DA HYDRO ALUNORTE
}

\section{LARGE PROJECTS IN BARCARENA-PA: SOCIO-ENVIRONMENTAL IMPACTS CAUSED BY THE ACTIVITIES OF HYDRO ALUNORTE}

\author{
GRANDES PROYECTOS EN BARCARENA-PA: IMPACTOS \\ SOCIOAMBIENTALES CAUSADOS POR LAS ACTIVIDADES DE LA HYDRO
} ALUNORTE

\author{
Mailson Lima NAZARÉ ${ }^{1}$ \\ Paula Mayara_Rodrigues do NASCIMENTO2 \\ Rafael Santos PENHA ${ }^{3}$
}

\begin{abstract}
RESUMO
O presente trabalho se desenvolve em comunidade tradicional no município de Barcarena no Estado do Pará, parte da análise de impactos socioambientais provocados por empresas de projetos multinacionais. Teve uma abordagem qualitativa, com entrevistas semiestruturadas, observação participante, técnica de livre narrativas e registros fotográficos, envolvendo pesquisa bibliográfica, documental e de campo. $\mathrm{O}$ lócus da pesquisa foi a comunidade tradicional de Boa Vista localizada no município de Barcarena-Pa, na qual examina-se o contexto de implantação de grandes projetos, seus impactos à bacia hidrográfica da região e a relação com os saberes na sociabilidade dos moradores. Problematizaremos a partir do vazamento dos rejeitos da empresa Hydro na região e as transformações causadas na comunidade. A justificativa foi de fazer a análise da relação entre os impactos ambientais e os saberes locais nos espaços sociais de pertencimentos. Como resultado, verificou-se que impactos ambientais influenciaram no imaginário da comunidade, e uma das principais questões preponderantes é a relação com a natureza, principalmente com o rio que os margeiam como elementos de construções de saberes e resistências.

Palavras-chave: Comunidade tradicional; Saberes; Impactos ambientais.
\end{abstract}

\footnotetext{
${ }^{1}$ Licenciado em Pedagogia pela Universidade do Estado do Pará (UEPA). Especialista em Saberes Africanos e Afro Brasileiro na Amazônia e pesquisador do Grupo de Pesquisa em Educação e Meio Ambiente (GRUPEMA). Email: mailson@uepa.br

${ }^{2}$ Licenciada em Geografia pela Universidade do Estado do Pará (UEPA) e pesquisadora do Grupo de Pesquisa em Educação e Meio Ambiente (GRUPEMA). Email: paulamayara95@gmail.com

${ }^{3}$ Licenciado em Geografia pela Universidade do Estado do Pará (UEPA). Mestrando em Geografia pela Universidade Federal do Pará (UFPA) e pesquisador do Grupo de Pesquisa em Educação e Meio Ambiente (GRUPEMA). Email: rafaelpenha27@gmail.com
} 
Mailson Lima NAZARÉ; Paula Mayara Rodrigues do NASCIMENTO; Rafael Santos PENHA

\begin{abstract}
The present work is carried out in a traditional community in the municipality of Barcarena in the State of Pará, part of the analysis of social and environmental impacts caused by multinational project companies. He had a qualitative approach, with semi-structured interviews, participant observation, free narrative technique and photographic records, involving bibliographical, documentary and field research. The locus of the research was the traditional community of Boa Vista located in the municipality of Barcarena-Pa, which examines the context of implementation of large projects, their impacts to the watershed of the region and the relationship with knowledge in the sociability of the residents. We will problematize from the leakage of the tailings of the Hydro company in the region and the transformations caused in the community. The justification was to analyze the relationship between environmental impacts and local knowledge in the social spaces of belonging. As a result, it was verified that environmental impacts influenced the community's imagination, and one of the main issues is the relationship with nature, especially with the river that borders on them as elements of knowledge and resistance
\end{abstract}

Keywords: Traditional community; You know; Environmental impacts.

\title{
RESUMEN
}

El presente trabajo se desarrolla en comunidad tradicional en el municipio de Barcarena en el Estado de Pará, parte del análisis de impactos socioambientales provocados por empresas de proyectos multinacionales. En el caso de las mujeres, la mayoría de las veces, la mayoría de las veces, El lusus de la investigación fue la comunidad tradicional de Boa Vista ubicada en el municipio de Barcarena-Pa, en la que se examina el contexto de implantación de grandes proyectos, sus impactos a la cuenca hidrográfica de la región y la relación con los saberes en la sociabilidad de los habitantes. Problematizaremos a partir de la fuga de los desechos de la empresa Hydro en la región y las transformaciones causadas en la comunidad. La justificación fue de hacer el análisis de la relación entre los impactos ambientales y los saberes locales en los espacios sociales de pertenencias. Como resultado, se verificó que impactos ambientales influenciaron en el imaginario de la comunidad, y una de las principales cuestiones preponderantes es la relación con la naturaleza, principalmente con el río que los marge como elementos de construcciones de saberes y resistencias.

Palabras clave: Comunidad tradicional; conocimiento; Impactos ambientales.

\section{INTRODUÇÃO}

O processo de ocupação da Amazônia e a degradação ambiental crescente vêm tornando-se elementos de preocupação de amplos setores da sociedade, como da academia, em face da consequente crise ambiental que vem ocasionando a diminuição da qualidade de vida das populações humanas e naturais, estas ocupações a partir da segunda metade do século XX se desenvolvem diante das políticas de instalação de grandes projetos e empreendimentos capitalistas na região, que segundo Chagas (2013), estas políticas que se pautam pelo discurso do desenvolvimento e da integração nacional vai ocasionar a crescente relocalização de 
Mailson Lima NAZARÉ; Paula Mayara Rodrigues do NASCIMENTO; Rafael Santos PENHA

atividades industriais dos países "centrais" para alguns países "periféricos" que atendessem a algumas exigências ocasionais, entre elas mão-de-obra barata e recursos minerais abundantes.

Desta forma, como tem acontecido ao longo da história, essa ocupação também ignora que a região amazônica estava ocupada por habitantes originários e tradicionais que sobreviviam da relação com a natureza, em especial do extrativismo, transformando a Amazônia em um espaço de produção e reprodução dos lucros capitalistas no processo de exploração dos recursos naturais por grandes empresas multinacionais aqui instaladas. "Foram políticas autoritárias e concentradoras de renda e de terras, que excluíam ou ignoravam a vida, a cultura e os interesses das classes pobres rurais e urbanas da Amazônia" (LOUREIRO, 1992, p. 69).

Diante desse quadro, essa pesquisa se desenvolve na Amazônia brasileira, precisamente na comunidade tradicional de Boa Vista no município de Barcarena situado no nordeste paraense a $16 \mathrm{~km}$ da capital, Belém. Trata-se de um estudo de caso que envolve possíveis crimes ambientais causados pela empresa multinacional norueguesa Hydro Alunorte, a maior refinaria de alumínio do mundo, instalada nas dependências do município de Barcarena desde 1995.

Para o Ministério Público do Estado do Pará (2018), as atividades industriais da empresa Norueguesa, NORSK HYDRO BRASIL - HYDRO ALUNORTE, no referido município apresentaram indicativos de severos danos ambientais às comunidades locais. Esses danos que causam degradação ambiental à região tornaram-se evidentes a partir das fortes chuvas que atingiram o Estado do Pará, em fevereiro de 2018, particularmente o município de Barcarena, causando denúncias de vazamento dos rejeitos da empresa Norueguesa Hydro, pelas comunidades, e noticiadas pelos veículos de imprensa, sendo apurado pelos órgãos de controle como o Ministério Público Federal (MPF), Ministério Público do Estado do Pará (MPE), Defensoria Pública do Estado do Pará (DPE) e Comissões Parlamentares de Inquéritos (CPI’s) da Assembleia Legislativa do Estado do Pará e do Congresso Nacional, após laudo inicial de vistoria técnica ${ }^{\circ}$ 002/2018 do Instituto Evandro Chagas (IEC), órgão público vinculado ao Ministério da Saúde do Governo Federal, conforme relatado em recomendações dos órgãos públicos de justiça.

CONSIDERANDO as denúncias de um possível extravasamento de resíduos ocorrido no dia 17/02/2018, provenientes da empresa Hydro Alunorte, produtora de alumina, 
Mailson Lima NAZARÉ; Paula Mayara Rodrigues do NASCIMENTO; Rafael Santos PENHA

atingindo vários pontos do município de Barcarena, conforme relatado por moradores e tendo em vista os elementos coletados in loco pelo Promotor de Justiça plantonista de Barcarena Laércio Guilhermino de Abreu e sua equipe técnica e confirmado pelo Instituto Evandro Chagas, conforme Nota Técnica SAMAM-IEC no 002/2018 (MPPA; MPF; DPEP, 2018, p. 23).

Neste sentido, inicialmente realizamos pesquisa bibliográfica, para subsidiar teoricamente o estudo, e documental a partir dos laudos, relatórios, recomendações e sentenças dos órgãos públicos, de controle e de justiça. Realizamos atividades de campo em audiência pública realizada em 22 de março de 2018 pelos Ministérios Públicos na Vila dos Cabanos, distrito de Barcarena, e pesquisa junto a Superintendência do Patrimônio da União no Pará (SPU-PA), assim como na comunidade tradicional Boa Vista, lócus desta pesquisa em que desenvolvemos uma abordagem qualitativa, com entrevistas semiestruturadas, observação participante, técnica de livre narrativas com registros fotográficos.

Assim sendo, a pesquisa contextualiza o cenário socioespacial da região amazônica brasileira, na perspectiva dos impactos de grandes projetos "desenvolvimentistas" na atualidade. Em seguida buscamos diagnosticar os indicativos de impactos ambientais ocasionados pela empresa Hydro Alunorte na bacia hidrográfica que envolve a comunidade Boa Vista e na última parte procuramos apresentar a relação de sociabilidade local e os saberes da comunidade frente aos impactos ocasionados pelas atividades industriais da empresa, objeto do estudo.

Evidencia-se que a relação da comunidade com a bacia hidrográfica é de fundamental importância para sua sobrevivência, pois a degradação dela altera o ecossistema com extinção de espécies animais e vegetais, alterando suas relações de sociabilidades, entre elas, as culturais e de identidade com o território.

\section{AMAZÔNIA E OS INTERESSES DO GRANDE CAPITAL}

A Amazônia sempre foi objeto de interesse pelo grande capital que se utilizou de estratégias diversas para legitimar sua ocupação, como a do discurso da modernização, desenvolvimento e integração, para Becker (1994, p.64) em "face à nova ordem econômica e tecnológica, a Amazônia constitui-se como espaço geopolítico privilegiado para as corporações transnacionais", na qual suas relações se baseiam muitas vezes na força do capital hegemônico. 
Mailson Lima NAZARÉ; Paula Mayara Rodrigues do NASCIMENTO; Rafael Santos PENHA

Chagas (2013) avalia que as riquezas naturais da Amazônia são motivos para transformá-la em uma das principais áreas de cobiça do Estado e do grande capital. Desta forma, esse interesse pela Amazônia se fundamenta pela sua rica biodiversidade e em grande escala pela mineração.

Isso se dá pela Amazônia legal ocupar 59\% do território brasileiro onde suas riquezas são incontáveis, sendo o olhar internacional e dos grandes mercados sempre voltados para o interior do Brasil e mais ainda para o interior amazônico. (MATTOS, 1992, p. 131-132)

Neste sentido a partir da segunda metade do século XX o Brasil envolvido na expansão capitalista mundial, atravessa diversos momentos econômicos como o que denominou-se de "milagre econômico", uma fase de rápido crescimento econômico entre os anos de 1968 e 1973. Entretanto, segundo Loureiro (2014, p. 324-325), ao final do ano de 1972 deu-se o primeiro colapso no preço do petróleo, com um aumento por volta de $400 \%$ no preço do barril dos países árabes, causando um grande desequilíbrio em toda a economia mundial.

Em meio a este contexto, o governo brasileiro alinhado ao discurso de desenvolvimento, crescimento econômico e progresso, buscando obter ritmos de crescimento lança os Planos Nacionais de Desenvolvimento (PND) que visam regular a economia frente à crise internacional e baixar a dependência brasileira em relação ao petróleo.

Vale lembrar que a grande dependência energética do Brasil era quase que $80 \%$ proveniente do petróleo elevando os custos de sua produção no período da crise. Isso empurrou o país para investir então na produção de novas fontes de energia que fossem capazes de substituir ou ao menos diminuir consideravelmente a dependência brasileira do petróleo e sua importação.

Sendo assim, estes fatores somados às estratégias de desenvolvimento do Estado farão da Amazônia, principalmente a partir desse período, um lócus de exploração energética e dos recursos naturais, atraindo assim o capital estrangeiro. O Estado desta forma não esboça preocupação com o equilíbrio ambiental e com as comunidades Amazônicas, privilegiando um formato de desenvolvimento em que há facilidade de acumulação financeira pelos detentores do capital, caracterizando a inserção dos grandes projetos na Amazônia em um novo arranjo socioespacial. 
Mailson Lima NAZARÉ; Paula Mayara Rodrigues do NASCIMENTO; Rafael Santos PENHA

\section{O MUNICÍPIO DE BARCARENA E O NOVO ARRANJO SOCIOESPACIAL}

Em meados de 1980 surgiu então o projeto Albrás e Alunorte no município de Barcarena, no Estado do Pará. O empreendimento industrial através da Alunorte processava a Bauxita para a produção de Alumina (produto intermediário) e a Albrás transformava a Alumina em Alumínio. A criação desse projeto é resultado da aliança entre o Brasil e o Japão, onde esse último com sua extensão territorial pequena sempre dependeu de fontes de recursos naturais de outros países, e ao ser afetado fortemente pelos altos preços do barril de petróleo na crise da década de 70 , teve o seu parque industrial de produção de alumínio em crise pela grande demanda de energia, transferindo-os aos países tidos como periféricos.

Com a crise o Japão grande consumidor de alumínio começa a fechar as suas unidades industriais do metal primário e a transferir suas unidades para os países periféricos onde o fator energia, mão-de-obra, legislação ambiental fossem atraentes. (BARROS, 2009, p. 42).

Esse novo arranjo socioespacial é resultado, como já visto, do desenvolvimento capitalista na região amazônica e a sua constituição foi seguida da construção de infraestruturas para atender os novos empreendimentos, como hidrelétricas, rodovias, portos, aeroportos, ferrovias e vilas operárias, como o caso da Vila dos Cabanos no município de Barcarena.

Desta forma, o projeto a Albrás-Alunorte no município de Barcarena tem hoje como principal acionista a empresa norueguesa NORSK HYDRO BRASIL LTDA, com 51\% das ações dessa joint venture, possuindo $92 \%$ do capital social, que também tem como acionista um consórcio de empresas japonesas a NAAC - Nippon Amazon Aluminium Co. Ltd. (MPF; MPPA, 2018, p.23).

Neste arranjo espacial gerenciado pelo Estado brasileiro, sobre a retórica de desenvolvimento regional de racionalidade hegemônica excludente que visa a exploração dos recursos naturais da Amazônia o município de Barcarena se incorpora. 
Mailson Lima NAZARÉ; Paula Mayara Rodrigues do NASCIMENTO; Rafael Santos PENHA

Figura 1. Complexo industrial da Hydro Alunorte em Barcarena.

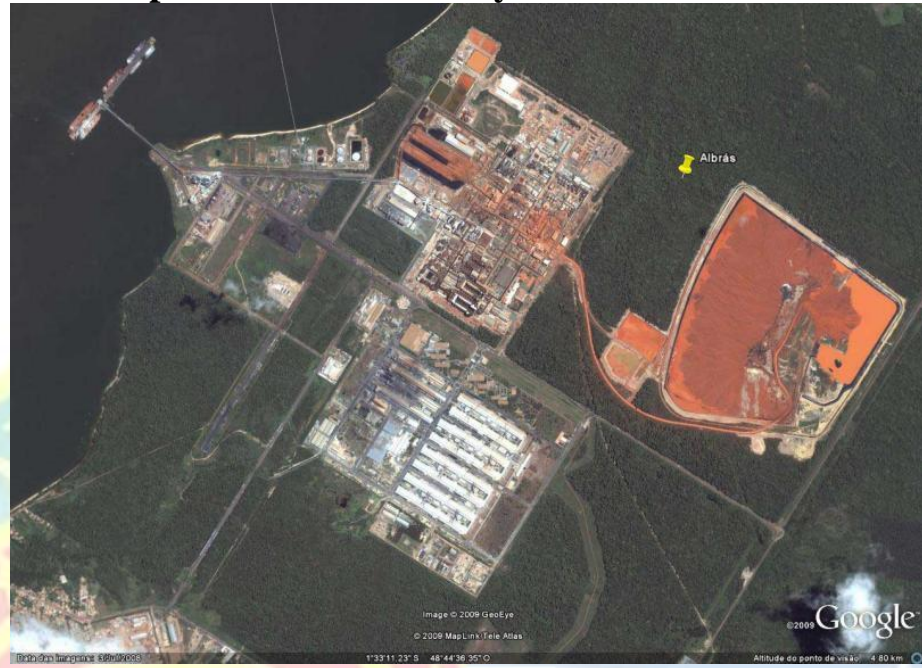

E dentro desta perspectiva questiona-se sobre o que aconteceu com quem vivia nestas áreas que vieram a ser a Vila dos Cabanos e todo o complexo industrial Albras-alunorte em Barcarena, pois nestas áreas habitavam comunidades tradicionais rurais que viviam da agricultura, pesca artesanal, caça e extrativismo vegetal.

Na prática estas comunidades observam o Estado privilegiar a relação com o capital e as classes dominantes, ao constituírem-se aparelhos institucionais como a Companhia de Desenvolvimento Industrial do Estado do Pará (CDI) responsável pela desapropriação da área e a Companhia de Desenvolvimento de Barcarena - CODEBAR, que segundo o relatório da SPU/PA (2013) era o órgão Federal que detinha a titularidades das terras podendo comercializá-las, pois tinha como finalizada a ordenação urbanística para a implementação da Vila dos Cabanos, invisibilizando e não reconhecendo as comunidades locais. Estas situações vão gerar diversos conflitos na atualidade como o citado na sentença de 6 de abril de 2017, do Tribunal de Justiça Federal da Primeira Região, no qual a comunidade Sítio São João solicita junto ao Instituto Nacional de Colonização e Reforma Agrária (INCRA), o reconhecimento e a titulação como Remanescente de Quilombo (TRF1, 2017) .

Segundo Barros (2009, p.43), após os governos do Brasil e Japão assinarem acordo de cooperação para a construção de um complexo produtor de alumínio no Estado no Pará, é em

\footnotetext{
${ }^{4}$ Processo No 0030774-26.2016.4.01.3900 - 2 ${ }^{\mathrm{a}}$ VARA FEDERAL de Belém.
} 
Mailson Lima NAZARÉ; Paula Mayara Rodrigues do NASCIMENTO; Rafael Santos PENHA

1977 que começam as transformações territoriais na área com a edição do decreto nº 10064 de 24/04/1977 do governo do Estado do Pará que manda desapropriar 40.000 hectares do polígono onde seria instalado o complexo industrial.

O decreto atingiu uma população tradicional que vivia nos seus lotes de terra tradicionalmente transferidos de pai para filho. É importante destacar que a ação da Companhia de Desenvolvimento Industrial do Estado do Pará (CDI) responsável pela desapropriação da área, não se deu de forma pacífica, ao contrário houve bastante resistência e discordância com os valores pagos pelos lotes de terra. Em Vila Murucupi (Vila do Conde), assim como nas demais áreas, esse processo veio a comprometer toda a produção ali existente (BARROS, 2007, p.183).

Nota-se que nesse novo arranjo socioespacial, o reordenamento territorial atinge diretamente a vida das comunidades locais, que são vistas como barreira às políticas de "desenvolvimento", ao avanço do capitalismo sobre a Amazônia e seus recursos naturais, consequentemente serão estas comunidades locais que sofreram os impactos das degradações ambientais oriundas do processo de industrialização na região, da relação contraditória destrutiva do homem sobre a natureza.

\section{OS IMPACTOS AMBIENTAIS CAUSADOS À BACIA HIDROGRÁFICA QUE} ABASTECE A COMUNIDADE BOA VISTA

A partir da chegada dos grandes projetos a realidade da Amazônia se caracteriza no que o pesquisador Marcelo Lima (2016, p.9) identifica de região de exposição e com histórico de impactos ambientais, é o que ocorre com a instalação do projeto Albrás/Alunorte, no município de Barcarena, que após fortes chuvas nos dias 16 e 17 do mês de fevereiro de 2018, as comunidades de seu entorno denunciam estarem sendo atingidas por possíveis crimes ambientais provenientes das atividades industriais da empresa, NORSK HYDRO BRASIL HYDRO ALUNORTE, entre as comunidades denunciantes está a tradicional Boa Vista, objeto deste estudo, que se constitui por moradores dos Sítios Boa Vista, São João, Cajueiro, Cupuaçu e Nazaré.

Essas denúncias foram feitas diretamente ao Ministério Público do Estado do Pará (MPPA), após as comunidades locais perceberem que haviam se acumulado, em diferentes pontos da cidade de Barcarena, água da chuva de coloração avermelhada, devido ao suposto vazamento de rejeitos de minérios de bauxita provenientes da empresa Hydro Alunorte, (figura 
Mailson Lima NAZARÉ; Paula Mayara Rodrigues do NASCIMENTO; Rafael Santos PENHA

2), desta feita tal incidente ocasiona o que denomina-se de impacto ambiental que terá como um principal atingido a bacia hidrográfica da região, afetando assim o ecossistema em que se situa a comunidade, tendo danos irreparáveis para suas vidas e para o meio ambiente. Para o Conselho Nacional do Meio Ambiente (1986), impacto ambiental é:

Qualquer alteração das propriedades físicas, químicas e biológicas do meio ambiente, causada por qualquer forma de matéria e energia resultante das atividades humanas que, direta ou indiretamente, afetam a saúde, a segurança, o bem-estar da população, as atividades sociais e econômicas, a biota, as condições estéticas e sanitárias do meio ambiente e a qualidade dos recursos ambientais (CONAMA, 1986, p. 1).

Figura 2. Indícios de transbordamento das bacias com rejeitos de bauxita da empresa Hydro Alunorte.

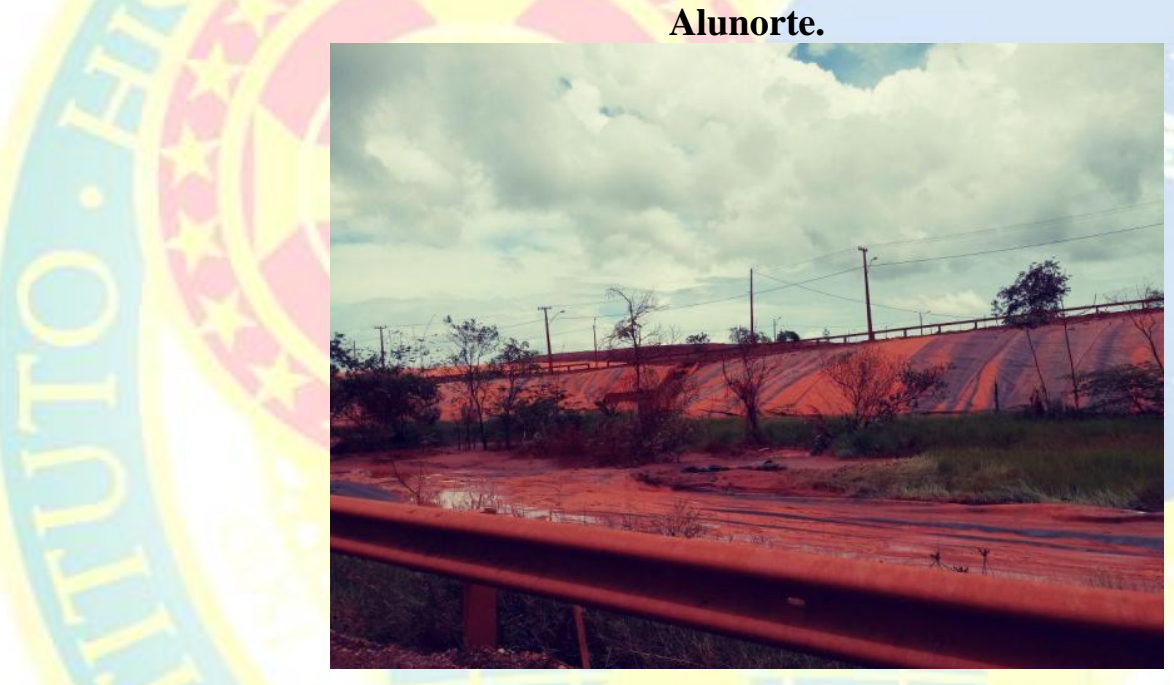

Fonte: Instituto Evandro Chagas, 2018.

As denúncias foram acolhidas pelos órgãos do Poder Judiciário, que em seguida acionaram o Instituto Evandro Chagas (IEC), órgão do Ministério da Saúde do Governo Federal, para que fossem feitas coletas de amostragem de água e efluentes, com a finalidade de apurar as possíveis contaminações.

Após serem coletadas as amostragens de água e efluentes em diferentes pontos, confirmou-se, através do laudo emitido em relatório técnico pelo IEC, a contaminação de diversas áreas de Barcarena, como evidencia-se em decisão do Tribunal de Justiça do Pará através do Ministério Público do Estado: 


\title{
Mailson Lima NAZARÉ; Paula Mayara Rodrigues do NASCIMENTO; Rafael Santos PENHA
}

A análise de amostras do material colhido no local, realizada pelo Instituto Evandro Chagas, demonstrou a presença de elevados níveis de chumbo, alumínio, sódio e outras substâncias prejudiciais à saúde humana e animal (TJPA/MPPA, 2018, p.4).

O referido relatório técnico (003/2018-IEC) do Instituto Evandro Chagas aponta ainda para bacias hidrográficas afetadas nos territórios de Barcarena e Abaetetuba, sendo elas dos rios Pará, Murucupi, São Francisco, Arienga, Arapiranga, Guajará do Beja, Maracapucu e Campupema. Estas bacias situam-se sobre influência do rio federal Tocantins ao leste e a oeste com a baia do Guajará que sofre influência do oceano atlântico, possuindo assim os terrenos marginais com influência de marés conhecidos como terrenos de marinha, jurisdição da União.

Evidencia-se ainda os impactos às bacias hidrográficas quando segundo o Ministério Público do Pará (Inquérito Civil n000980-040/2018), a empresa HYDRO/ALUNORTE confessa em comunicação à Secretaria de Estado de Meio Ambiente e Sustentabilidade (SEMAS), datada de 19/02/2018, que o incidente do dia 17/02/2018 não teria sido isolado, pois a empresa vinha utilizando um duto, conhecido como "canal reserva" ou "canal antigo" para lançar efluentes pluviais não tratados diretamente no Rio Pará.

Deste modo, demonstra-se que exploração mineral na região, caminhava exclusivamente para atender os lucros do mercado globalizado capitalista não havendo preocupação com as degradações às bacias hidrográficas que consequentemente vão alterar os elementos da natureza, desequilibrando o ecossistema, assim influenciando nas vidas dos moradores das comunidades locais.

Nesta direção o poder judiciário (MPF; MPPA), através dos inquéritos civis instaurados: Inquérito Civil MPF n: 1.23.000.000498/2018-98; Inquérito Civil - IC n001/2018-MP (SIMP nº00654-710/2018) MPPA; Inquérito Civil n 000980-040/2018 (Portaria nº 12/2018) MPPA, se manifesta:

\begin{abstract}
Concluindo em linhas gerais, que diversos metais tóxicos foram encontrados nas águas superficiais, em níveis acima dos considerados aceitáveis pela Resolução CONAMA 357/2005, atingindo diversos corpos hídricos, bacias, rios, igarapés e comunidades de toda a região, que vai de Barcarena a Abaetetuba, e que, portanto, implicam em danos ao ecossistema aquático e à saúde humana, indicando que as águas do rio Pará (áreas próximo às praias de Sirituba e Beja), Guajará do Beja, Arapiranga, igarapés Curuperê e Dendê e Tributário do Tauá e demais corpos hídricos, como o rio Murucupi, entre as nascentes e um ponto próximo a comunidade da Vila Nova, não podem ser usadas para recreação, pesca ou consumo humano (MPF; MPPA, 2018, p.16).
\end{abstract}

Figuras 3 e 4. Duto clandestino e área de despejo. 

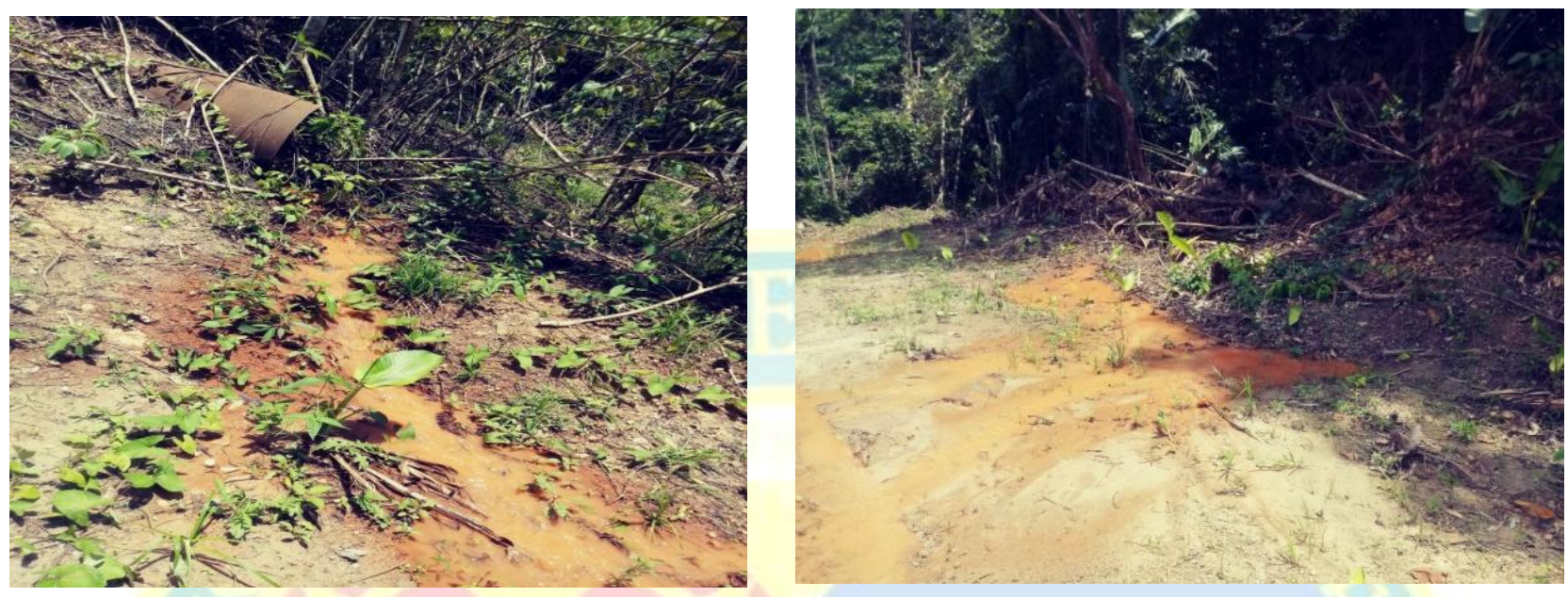

Fonte: Instituto Evandro Chagas, 2018.

Estes metais de acordo com o laudo do IEC, com índices elevados, são sódio, nitrato e alumínio. Além da alta concentração de chumbo nas águas coletada dos poços das comunidades atingidas. Para Lago e Pádua (1993, p.80), entre os elementos mais perigosos lançados nas águas por atividades industriais ou de mineração se encontram o mercúrio, o cádmio, o chumbo e o arsênio, para os autores esta realidade de degradação ambiental e impunidade pelos grandes empreendimentos capitalistas já são recorrentes no Brasil.

[...] indústrias de vários tipos têm lançado compostos inorgânicos e metais pesados nas águas brasileiras de forma praticamente impune, causando verdadeiros estragos ecológicos. Basta lembrar a contaminação do rio Subaé (BA) pelo chumbo e pelo cádmio despejados pela Companhia Brasileira de Chumbo (que apesar do nome patriótico é uma multinacional ligada ao grupo francês Pennaroya) [...] (LAGO; PÁDUA, 1993, p.81).

Diante desta situação é que se encontra a bacia hidrográfica do rio Murucupi, que ao sofrer influências da sazonalidade das marés se relaciona com as demais bacias e ao abastecer a comunidade tradicional Boa Vista, transfere também os impactos à comunidade, o que é algo extremamente preocupante, pois esta comunidade utiliza suas águas e de seus igarapés para a pesca, lazer, entre outras atividades, situação que vai alterando o espaço de sociabilidade da comunidade, constituindo-se um processo que o geógrafo Milton Santos (1987), em seu livro "O Espaço do Cidadão", aborda sobre as transformações estabelecidas na paisagem e no meio 
Mailson Lima NAZARÉ; Paula Mayara Rodrigues do NASCIMENTO; Rafael Santos PENHA

ambiente, que são fruto dos processos produtivos, cujos resultados ofendem, expulsam e desenraízam as pessoas.

\section{SOCIABILIDADE LOCAL E A RELAÇÃO DOS SABERES DA COMUNIDADE BOA VISTA COM OS IMPACTOS AMBIENTAIS}

Ao buscarmos investigar os diferentes saberes e sociabilidades na comunidade tradicional Boa Vista em Barcarena, e a relação com os impactos ambientais realizamos pesquisa de campo in loco, no dia 16 de junho de 2018 objetivando elaborar um trabalho investigativo que procurasse representar cientificamente a vivência do cotidiano da comunidade.

A comunidade, em meio a uma exuberante natureza, se localiza entre o ramal do Cupuaçu e as margens do rio Murucupi, possuindo 91 famílias, segundo registros do relatório da Superintendência do Patrimônio da União no Pará, SPU-PA (2013), e com seus modos simples de viver desenvolvem suas relações de sociabilidades interagindo com o meio ambiente, tendo nos seus saberes as formas de resistência, pertencimento e identidade ao seu território.

E buscando atingir o trabalho de campo proposto percorremos os sítios São João, Cajueiro, Nazaré e Boa Vista, da comunidade, em que realizamos as atividades metodológicas de entrevistas semiestruturadas (utilizaremos abreviaturas dos nomes dos entrevistados), observação participante, técnica de livre narrativas e registros fotográficos.

Nestes sítios da comunidade pudemos observar a ancestralidade e a tradicionalidade que configura o território, conforme registra o relatório de órgão federal de regularização fundiária.

[...] as pessoas que residem no local atualmente são membros ou agregados de uma mesma família descendentes de Cordolino da Silva Pinheiro e Odócia da Costa Pinheiro, os quais nasceram e viveram na mesma localidade (SPU, 2013, p.4).

Destaca-se que por sua ancestralidade, a comunidade tem a sua relação com "a terra com parte indissociável de suas existências, tendo habitado nela por gerações seguidas, sem jamais se terem perguntado pela existência de donos mais legítimos que eles próprios" (LOUREIRO, 1992, p.11), pois o lugar preserva diversos saberes, costumes e características ecológicas tradicionais, com vegetação de árvores de pequenos portes, áreas de campos abertos, 
Mailson Lima NAZARÉ; Paula Mayara Rodrigues do NASCIMENTO; Rafael Santos PENHA

mangues e matas ciliares, sendo banhada pelo rio Murucupi com seus braços de igarapés como o Cajueiro.

Ao registrar o cotidiano da comunidade, pudemos observar a existência de energia elétrica e poços artesianos (muitos com profundidades de até três metros) nas residências dos sítios, a prevalência de trabalho comunitário em mutirões familiares, relações religiosas, criações de animais de pequeno porte, plantações e roças de mandioca, casas de farinha e pequenas carvoarias, pesca e caça como forma de subsistências, estas últimas atividades desenvolvidas já com dificuldades, impactadas pelos empreendimentos industriais que afetam a bacia hidrográfica da região.

Figura 5. Roça de mandioca na comunidade boa vista.

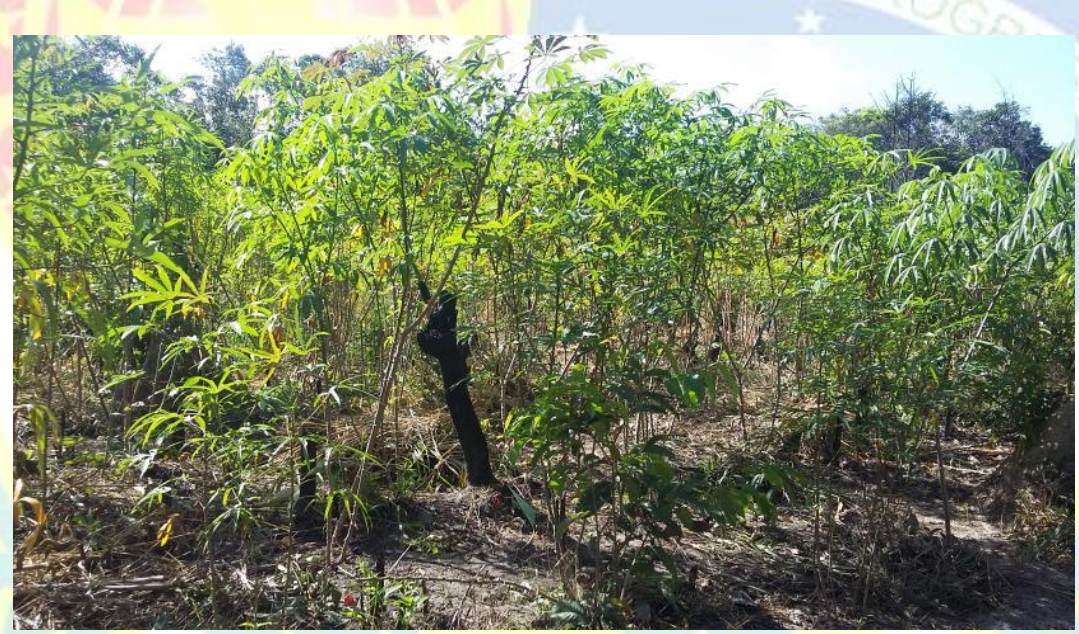

Fonte: Pesquisa de campo, 2018.

As transformações sociais da sociedade "moderna civilizada" e as situações de irregularidades das atividades industriais da empresa Hydro Alunorte estão transformando profundamente as relações socioambientais da comunidade, como nos relata uma das moradoras do Sítio Cajueiro:

Eu gosto do mato, tenho roça, mas os açaizeiros não estão dando nada, as caças afugentaram desde que eles chegaram aqui (as empresas) os peixes do rio tá poluído, mas os moradores lá de baixo são mais afetados porque estão mais perto do rio (J.C.S, 77 anos, entrevista realizada em junho de 2018). 


\section{Mailson Lima NAZARÉ; Paula Mayara Rodrigues do NASCIMENTO; Rafael Santos PENHA}

Entre os saberes identificados no Sítio Cajueiro, está o que relaciona-se com o sagrado, em rituais místicos de benzedeiras e realização de festividades todos os anos, com ladainhas, e crenças ao padroeiro da comunidade, São Benedito para agradecer uma promessa de cura, desenvolvendo sociabilidade na comunidade, assim como a busca de proteção dos fenômenos naturais como chuvas, tempestades, trovões e relâmpagos.

Meu marido tinha uma doença e foi desenganado em Belém, voltou para morrer e se apegou ao Santo, que se ele desce a cura dele ia fazer uma ladainha todo ano par ele, foi com benzedeiro e usou os remédios do sítio, ele se curou e falou vou fazer uma ladainha e dá um porco para o Santo, ele pagou a promessa e eu falei bora continuar a festa e todo ano fazemos a festividade do São Benedito (J. C. S, 77 anos, entrevista realizada em junho de 2018).

No sítio São João, encontramos o senhor E.M.S.S. de 67 anos, em meio a criação de animais de pequenos porte, como galinhas e patos, com sua família produzindo farinha, o que demonstra as práticas socioambientais locais. Neste sítio localiza-se o igarapé cajueiro, conforme identificamos.

O igarapé segundo os moradores era utilizado diretamente para a manutenção de seus modos de vida, de sua relação identitária com a natureza, de suas estratégias de manutenção locais.

O igarapé Cajueiro, braço do Murucupi, sempre foi uma fonte de vida, de onde tirávamos água para beber, tomar banho e pescar, mas é hoje fonte de preocupação pelas incidências dos desastres ambientais causados pelos rejeitos de metais oriundos da empresa Hydro como outros acidentes que já ocorreram na região matando muitos peixes. (E.M.S.S. de 67 anos, entrevista realizada em junho de 2018).

Ao ser indagado por nós, sobre os transtornos causados por este último acidente ambiental, o senhor E.M.S.S. nos relatou vários problemas enfrentados por ele e sua família, dentre eles, de saúde, como uma enfermidade na pele de seu corpo, que, segundo ele, fora causada após o uso da água contaminada após o acidente ambiental e por causa disto ele e sua família não estavam mais utilizando a água do igarapé, o que fazia se sentirem prejudicados.

O morador E.M.S.S., relata ainda a falta de assistência do poder público, pois sua família não havia sido visitada, ou recebido algum auxílio da empresa Hydro e nem dos órgãos públicos como água potável, por exemplo.

No sítio Nazaré ao conversarmos com o senhor B.A.S. de 75 anos, que reside nas proximidades das margens do Rio Murucupi, o mesmo nos diz que utiliza água de poço porque: 


\section{Mailson Lima NAZARÉ; Paula Mayara Rodrigues do NASCIMENTO; Rafael Santos PENHA}

O rio não presta mais, sua nascente nos campos da Alunorte está contaminado, aqui não tem peixe e nem camarão mais, e utilizamos o rio com transporte gastando 10 minutos de canoa até o laranjal e pela estrada 30 minutos de bicicleta para a área urbana (B.A.S. de 75 anos, entrevista realizada em junho de 2018).

Destaca-se ainda que o senhor B.A.S., problematizou sobre a morosidade dos órgãos públicos para resolver a situação fundiária dos moradores, situação que eles enfrentam desde a chegada dos empreendimentos industriais, e que há anos reivindicam seus direitos de titulação da área.

Observamos no sítio Boa Vista em sua paisagem as plantações de cacau, laranja, limão, hortas, plantas medicinais e de jardinagem, refletindo a densa relação com a natureza, onde encontramos os moradores E.P.A., uma senhora com 84 anos, nascida no local, que nos relatou que sua família é uma das primeiras a chegar na localidade, e o senhor B.P.A, 74 anos, o qual, nos informou como utilizam o rio Murucupi mesmo sabendo das preocupantes mudanças que vem ocorrendo na comunidade pelas degradações ambientais.

A poluição aqui já matou muito peixe e camarão, mas continuamos aqui e quando dá a gente pega peixe; a água tá contaminada não dá mais para tomar banho, mas os meninos tomam de teimosos, agente (sic) usa água do poço. (B. P. A., 74 anos, entrevista em junho de 2018).

Nota-se que os moradores da comunidade tradicional Boa Vista, se identificam e se relacionam, com os impactos ambientais que lhes atingem, e que os problemas evidentemente trazidos pela empresa Hydro à comunidade são refletidos nos seus saberes socioambientais, pois influencia seus modos de vida que se baseiam no extrativismo e nas práticas de subsistências.

Nessa perspectiva, o ecossistema começa e se alterar a partir do rio Murucupi, que é um elemento central de suas sobrevivências, extinguindo espécies animais e vegetais, altera-se suas relações de sociabilidades, pois é dele que se tira a alimentação, e se utiliza suas águas nos afazeres domésticos e de lazer, como uma extensão de suas formas de viver.

Nesta direção se apresenta preocupação também no que se refere ao lençol freático que envolve a comunidade, pelo fato de culturalmente utilizarem poços abertos sem profundidades, tendo a possibilidade destes possuírem águas superficiais com qualidades já comprometidas, como as identificadas em outras comunidades tradicionais na região, conforme laudos do IEC. 


\section{Mailson Lima NAZARÉ; Paula Mayara Rodrigues do NASCIMENTO; Rafael Santos PENHA}

Este ambiente complexo imposto pelo grande capital à Amazônia, que em sua relação exploração e degradação, tem como consequência a negação de direitos e a invisibilidade das comunidades locais, pautando-se pela visão eurocêntrica que coloca as comunidades tradicionais como o atraso ao "desenvolvimento", tem nos saberes e práticas socioambientais locais suas formas de resistência, quando, por exemplo, pautam a definição em definitivo de domínio e titulação das terras que ocupam há anos, colocando no centro suas pautas, enfrentando o pensamento hegemônico. É nesta perspectiva de resistências que as comunidades tidas como periféricas pelos pensamentos hegemônicos desenvolvem seus saberes, que segundo Santos (2010, p.152):

[...] é nessas áreas que os saberes não hegemônicos e os seus titulares mais necessidades têm de fundar a sua resistência em processos de autoconhecimento que mobilizam o contexto social, cultural e histórico mais amplo que explica a desigualdade, ao mesmo tempo em que gera energias de resistência contra ela.

Desta forma a comunidade tradicional Boa Vista, se configura com seus saberes em um instrumento de busca e afirmação de identidade, ao enfrentar os impactos ambientais causados pela empresa Hydro Alunorte, procurando manter seus ambientes de sociabilidade, em um contexto complexo.

\section{CONSIDERAÇÕES FINAIS}

Observa-se que a partir da introdução dos grandes projetos na região há uma significativa intervenção nos saberes e nas práticas socioambientais na comunidade tradicional Boa Vista, interferido no uso racional dos recursos naturais pela comunidade. O que se agrava com as degradações ambientais ocasionadas pelas atividades industriais da empresa Hydro Alunorte.

Em meio a este contexto surgem manifestações diversas sobre o caso, como a negativa dos impactos ambientais pela empresa, que se contesta pelos laudos do IEC e relatórios dos MP's, e trabalhos de campo realizados.

Surgem também percepções de que a região sofre impactos pelos processos antrópicos, em que se manifesta nesta direção um comitê constituído pela Casa Civil do Governo Federal 
Mailson Lima NAZARÉ; Paula Mayara Rodrigues do NASCIMENTO; Rafael Santos PENHA

através do Decreto $\mathrm{n}^{\circ}$ 9.316/2018 para avaliar o meio ambiente na região, o que não deixa de ser pertinente em meio aos processos urbanização e industrialização da sociedade capitalista.

O comitê com a coordenação da Casa Civil da Presidência da República, e como integrantes o Ministério da Integração nacional, Ministério de Direitos Humanos e Ministério do Meio Ambiente se apresenta com o objetivo de:

[...] acompanhar as ações de socorro e assistência, reestabelecimento de serviços essenciais afetados, monitoramento e recuperação, e reconstrução decorrentes da contaminação ambiental ocorrida no município de Barcarena (CASA CIVIL DA PRESIDÊNCIA DA REPÚBLICA, 2018, p.2).

Em seu o relatório, o Comitê da Casa Civil da Presidência da República (2018) aponta que a região já vem sendo acometida por diversos eventos acidentais nos últimos dez anos, com a liberação de poluentes para o meio ambiente, o que demonstra um descaso com as comunidades tradicionais, pois além de se limitarem percorrem apenas às comunidades mais próximas do em torno com complexo industrial, Bom Futuro e Vila Nova, só em 01/05/2018 o Governo Federal decreta situação de emergência. Assim, em suas conclusões o relatório destaca que:

Existem três fontes de contaminação ambiental em Barcarena: 1- desastres e acidentes ambientais, responsáveis por picos de contaminação; 2- atividade industrial e 3lançamentos oriundos de ocupação urbana desordenada (CASA CIVIL DA PRESIDÊNCIA DA REPÚBLICA, 2018, p.9).

Evidentemente que estas questões vão ao encontro de nossas análises na comunidade Boa Vista, e desta forma apresentamos algumas constatações que se relacionam com os impactos ambientais e o cotidiano da comunidade, que mesmo se localizando mais distante do complexo industrial da empresa Hydro Alunorte, sofre direta e indiretamente as consequências de suas atividades:

Quadro 1. Relação atividades e impactos.

\begin{tabular}{|l|ll|}
\hline ATIVIDADES DESENVOLVIDAS & & \multicolumn{1}{c|}{ IMPACTOS OCASIONADOS } \\
\hline$>\begin{array}{l}\text { Exploração dos recursos naturais } \\
\text { como infinitos; } \\
\text { Desapropriações de terras; }\end{array}$ & $>\begin{array}{l}\text { Avanço das atividades industriais sobre às áreas das } \\
\text { comunidades originárias e tradicionais; }\end{array}$ \\
& $>\begin{array}{l}\text { Mudanças nas relações de sociabilidade na região; } \\
\text { Conflitos agrários e ambientais; }\end{array}$ \\
& $>\begin{array}{l}\text { Alteração no ecossistema local dificultando a caça e } \\
\text { pesca de subsistência, assim como a coleta de frutos }\end{array}$ \\
\hline
\end{tabular}




\begin{tabular}{|l|ll|}
\hline & \multicolumn{2}{|l|}{ da floresta pela comunidade. } \\
& \\
\hline $\begin{array}{l}\text { Despejo irregular de efluentes por } \\
\text { dutos clandestinos e transbordo de } \\
\text { estação de tratamento; }\end{array}$ & $>\begin{array}{l}\text { Contaminação da bacia hidrográfica que envolve a } \\
\text { comunidade Boa Vista; } \\
\text { Possíveis contaminações do lençol freático que } \\
\text { envolve os poços artesianos rasos, dos moradores. }\end{array}$ \\
\hline $\begin{array}{l}\text { Imposição de uma nova dinâmica } \\
\text { socioespacial. }\end{array}$ & $>\begin{array}{l}\text { Invisibilização das comunidades tradicionais e de } \\
\text { seus saberes socioambientais. }\end{array}$ \\
\hline
\end{tabular}

Quadro 2. Saberes e relações socioambientais da comunidade local.

\begin{tabular}{|l|ll|}
\hline \multicolumn{1}{|c|}{ SABERES IDENTIFICADOS } & \multicolumn{1}{|c|}{ FORMAS DE MANIFESTAÇÃO } \\
\hline $\begin{array}{l}\text { Saberes Religiosos (relação com } \\
\text { o sagrado para pagar promessas } \\
\text { e buscar proteção de fenômenos } \\
\text { naturais, como trovões e fortes } \\
\text { chuvas). }\end{array}$ & $>\begin{array}{l}\text { Festividades de santos católicos, São Benedito; } \\
\text { Recorrem a benzedeiras para buscar curas de } \\
\text { doenças. }\end{array}$ \\
\hline $\begin{array}{l}\text { Saberes Ambientais (relação } \\
\text { com a natureza como forma de } \\
\text { sobrevivência). }\end{array}$ & $>\begin{array}{l}\text { Utilizam os recursos da fauna e flora com forma de } \\
\text { subsistência; }\end{array}$ \\
& $>\begin{array}{l}\text { Fazem pequenas hortas, plantam mandioca, fazem } \\
\text { coletas de frutos e vegetais, e criam animais de } \\
\text { pequeno porte; } \\
\text { Rio Murucupi como a principal fonte de } \\
\text { sobrevivência da comunidade, sendo utilizada para } \\
\text { trafegar, fonte de alimentação, coleta de água para } \\
\text { afazeres domésticos e de lazer. }\end{array}$ \\
\hline Saberes Culturais & $>\begin{array}{l}\text { Identidade e pertencimento com o território nas } \\
\text { relações construídas com parentesco e vizinhanças; } \\
\text { Produções e utilização de atividades em casas de } \\
\text { farinhas e pequenas carvoarias. }\end{array}$ \\
\hline
\end{tabular}

Fonte: Pesquisa de Campo, 2018.

À luz das questões apresentadas, é que a comunidade tradicional Boa Vista desenvolve seus saberes, reconhecendo o significado que os recursos naturais presentes nesta região da Amazônia possuem para suas vidas. Em uma Amazônia diversificada que resiste às imposições 


\title{
Mailson Lima NAZARÉ; Paula Mayara Rodrigues do NASCIMENTO; Rafael Santos PENHA
}

que os grandes projetos de padrão capitalista se impõem, gerando degradação ambiental, exclusão social às comunidades locais e impondo suas visões de conhecimentos e verdades.

\begin{abstract}
Assim, quando se fala de Amazônia é preciso estar atento para sabermos de que Amazônia estamos falando, tendo em conta que os diferentes agentes que atuam na região, ou por ela se interessam, tentar propor/impor a sua visão do que seja a verdade da região como sendo a verdade da região. Esse jogo de verdades é parte do jogo de poder que se trava na e sobre ela (PORTO-GONÇALVES, 2001, p. 17).
\end{abstract}

Diante disso, a pesquisa revela as relações sociais da comunidade com a natureza, seu enraizamento com o local, e a necessidade de ter um olhar integrado sobre a Amazônia para se contrapor ao padrão de poder imposto pelas políticas de "desenvolvimento" dos grandes projetos.

\section{REFERÊNCIAS BIBLIOGRÁFICAS}

BECKER, B. K. Amazônia. 3. Ed. São Paulo, Ática, 1994.

BARROS, M. J. B. Vila do conde e a instalação dos projetos em Barcarena. In: MATHIS. A. (Org.) Poder local e mudanças socioambientais. Belém: NAEA/UFPA, 2007. p. 323.

Mineração, finanças públicas e desenvolvimento local no município de Barcarena-Pará. 2009. Dissertação (Mestrado em Geografia). Programa de Pós-Graduação em Geografia, Universidade Federal do Pará, Belém, 2012.

CASA CIVIL DA PRESIDÊNCIA DA REPÚBLICA. Comitê de Gestão e Avaliação de Respostas à Contaminação Ambiental nos municípios de Barcarena, ocorrido em Belém, Ananindeua e Barcarena, Estado do Pará. Disponível em: <www.casacivil.gov.br/central/relatorio_viagem_Barcarena.pdf〉. Acesso em: 16 set. 2018.

CHAGAS, C. A. N. O mito da cidade aberta: vila dos cabanos, urbanização e planejamento urbano na Amazônia. 1.ed. Belém: GAPTA/UFPA, 2013. p. 184.

CONSELHO NACIONAL DO MEIO AMBIENTE. RESOLUÇÃO No 001, de 23 de janeiro de 1986. Publicado no D. O. U. de 17/2/86. IBAMA. Disponível em: <http://www.cprh.pe.gov.br/ARQUIVOS_ANEXO/resolu\%C3\%A7\%C3\%A3o\%20conama\%200186; 1505;20100818.pdf>. Acesso em: 08 set. 2018.

INSTITUTO EVANDRO CHAGAS - IEC. Relatório no003/2018 Processo nº 010/2018. Avaliação preliminar dos impactos ambientes referentes ao tansbordo e lançamentos irregulares de efluentes de mama vermelha na cidade de Barcarena, Estado do Pará. Disponível em: $<\mathrm{http} / / / \mathrm{www}$.iec.gov.br/portal/coletiva-hydro-2/relatorio-tecnico-003-2018-final-tabelas-modificadas-s s-2/>. Acesso em: 07 jul. 2018. 
Mailson Lima NAZARÉ; Paula Mayara Rodrigues do NASCIMENTO; Rafael Santos PENHA

INSTITUTO NACIONAL DE COLONIZAÇÃO E REFORMA AGRÁRIA. Processo $\mathbf{N}^{\circ}$ 0030774-26.2016.4.01.3900 - $2^{\mathrm{a}}$ VARA FEDERAL de Belém. Disponível em: <https://mpf.jusbrasil.com.br/noticias/405340565/mpf-cobra-demarcacao-e-titulacao-de-quatro-comun idades-quilombolas-em-barcarena-pa >. Acesso em: 05 jun.2018.

LAGO, A; PÁDUA, J. A. O que é Ecologia. São Paulo, 12ªed. Brasiliense, 1993. p. 108.

LIMA, M. O. Amazônia, uma história de impactos e exposição ambiental em paralelo à instalação de grandes empreendimentos na região. Revista Pan-Amazônica de Saúde. Ananindeua. v. $7, \quad$ n. 2, p. 9-11, jun. 2016. Disponível em: <http://scielo.iec.gov.br/pdf/rpas/v7n2/2176-6223-rpas-7-02-00009.pdf >. Acesso em: 05 jun.2018.

LOUREIRO, V. R. Amazônia: estado, homem, natureza. Belém, PA: CEJUP, 1992. p. 367.

Amazônia: estado, homem, natureza. $3^{\text {a }}$ Ed. Belém, PA: Cultural Brasil, 2014. p. 383.

MATTOS, A. M. O interesse nacional e os interesses internacionais na Amazônia. In: COSTA, J. M. M. (Org.). Amazônia: desenvolvimento ou retrocesso. Belém: CEJUP, 1992. p. 351.

MINISTÉRIO PÚBLICO DO ESTADO DO PARÁ. Decisão Judicial. 2018. Belém. Disponível em: <http://www.mppa.mp.br/upload/Decisao\%20JUDICIAL.pdf.>. Acesso em: 05 jul. 2018.

MINISTÉRIO PÚBLICO FEDERAL; MINISTÉRIO PÚBLICO DO ESTADO DO PARÁ; DEFENSORIA PÚBLICA DO ESTADO DO PARÁ. Recomendação. 2018. Belém. Disponível em: $<$ http://www.mppa.mp.br/upload/Recomendacao\%20Vazamento\%20Hydro_MPPA-MPF-DP(1).pdf.

MINISTÉRIO PÚBLICO FEDERAL; MINISTÉRIO PÚBLICO DO ESTADO DO PARÁ. Pedido de Tutela de Urgência Cautelar Antecedente. 2018. Belém. Disponível em: $<$ http://www.mpf.mp.br/pa/sala-de-imprensa/documentos/2018/acao_cautelar_civel_forca-tarefa_mpf _mppa_vs_hydro_alunorte_10-04-18.pdf/view>. Acesso em: 05 jul. 2018.

MINISTÉRIO PÚBLICO ESTADUAL. Medida Cautelar Inominada. 2018. Belém. Disponível em: <www.mppa.mp.br/upload/Decisao\%20JUDICIAL.pdf>. Acesso em: 02 jul. 2018.

PORTO-GONÇALVES, Carlos Walter. Amazônia, Amazônias. São Paulo: Contexto, 2001. p. 176.

SANTOS, B. S. A gramática do tempo: para uma nova cultura política. São Paulo: Cortez, 2010.

SANTOS, M. O Espaço do Cidadão. 7. ed. São Paulo: EDUSP, 2007.

SUPERINTENDÊNCIA DO PATRIMÔNIO DA UNIÃO. Relatório de Situação da Comunidade Tradicional de Boa Vista. 2013. Belém. Arquivos SPU/PA. Disponível em: http://www.planejamento.gov.br/assuntos/patrimonio-da-uniao/regionais/spu-pa>. Acesso em: 06 jul. 2018. 